\title{
ERRATA
}

\section{Use of Rapid Acetoin Test in the Identification of Staphylococci and Micrococci}

\author{
G. H. G. DAVIS and BERYL HOYLING \\ Department of Microbiology, University of Queensland, Brisbane, Australia
}

\begin{abstract}
Volume 23, no. 3, p. 281, column 1, last 2 lines, and column 2, first 2 lines, should read: “. . onto agar containing: tryptone (Oxoid L42), $2 \%$; yeast extract (Oxoid L 21 ), $0.2 \%$; glucose, $1 \%$; Oxoid agar no. $1,1 \%$; pH 7.2."

Please substitue this erratum for the one published in volume 24 , no. 1 (January).
\end{abstract}

\section{Comparative Serological Studies Between a Newly Isolated Halophilic Leptospira and Two Other Leptospiras Isolated from Brackish Water}

\author{
M. CINCO, M. TAMARO, G. D. ROTTINI, and C. MONTI-BRAGADIN \\ Institute of Microbiology, University of Trieste, Trieste, Italy
}

Volume 24 , no. 1, p. 133 , first column, line 2: Change "adsorption" to read "absorption."

Page 134, Literature Cited: Change reference 3 to read "3. Castelli, M. 1969. Presenza di leptospire in acqua marina. Parassitologia 11:37-39." Change reference 8 to read "8. Mazzonelli, I., and M. Castellani. 1968. Efecto del bicarbonato de sodio en la diferenciacion de leptospiras saprofitas y patogenas. Veterinaria $4: 3-30 . "$

Page 134, Table 2, second column: Change "adsorbed" to "absorbed" throughout.

\section{Bifidobacterium catenulatum, Bifidobacterium dentium, and Bifidobacterium angulatum: Three New Species and Their Deoxyribonucleic Acid Homology Relationships

\author{
V. SCARDOVI and F. CROCIANI
} \\ Istituto di Microbiologia Agraria, Universita di Bologna, Italy}

Volume 24 , no. 1 , p. 8, column 2, line 9: Change "(60 C)" to read "(69 C)." Table 3, footnote $a$, line 2: Change "counts per min per g" to read "counts per min per $\mu \mathrm{g}$."

Page 10, column 1, paragraph 4, line 5: Change " $(0.1 \mathrm{~N}, \mathrm{pH} 7)$ " to read " $(0.1 \mathrm{M}, \mathrm{pH} 7)$."

Page 18, column 2, paragraph 9, lines 2 and 3: Change "maximum, 42 to $42 \mathrm{C}$ " to read "maximum, 42 to 43 C."

Page 19, column 1, paragraph 3, line 2: Change "(some 30\%)" to read "(some 20\%)." Paragraph 10, line 2: Change "maximum, 42 to $42 \mathrm{C}$ " to read "maximum, 42 to $43 \mathrm{C}$." 